\title{
Multivariate Grey PredictionModel with Priority Accumulation of New Information
}

\author{
Lanxi Zhang ${ }^{1 *}$ \\ ${ }^{1}$ School of Science, Southwest University of Science and Technology, Mianyang 621000, China.
}

\begin{abstract}
According to the new information priority principle of grey system, this paper tries to optimize the traditional multivariate grey prediction model. Firstly, the basic theory of the traditional grey prediction model is put forward. Based on this, the background value is improved by using the new information priority principle, and the cumulative generation with parameters is defined. Taking the settlement trend of A4\# building of an engineering project in Anhui province as an example, the model is applied to the settlement analysis, and the proposed model is compared with the existing grey prediction model, the average percentage absolute error between the predicted value and the observed value is calculated, and the regression graphs of each model are drawn. Through the analysis, we can see that the established model has achieved a good effect, and then verified the practicability and reliability of the proposed model.
\end{abstract}

\section{Introduction}

With the continuous development of China, China's industrial and civil construction industry has also made great progress, a variety of complex and large engineering buildings are increasing. The construction of the engineering building changes the original state of the ground and exerts a certain pressure on the foundation of the building, which causes the deformation of the foundation and surrounding stratum. In order to ensure the safe use of the building and provide data for the future reasonable design, therefore, the building settlement should be observed during the construction process and after the building is put into operation. The settlement observation of buildings is a complex process, which is affected by many factors, and each monitoring point also affects and restricts each other. With the attention and research on the observation of building subsidence, a variety of prediction methods have emerged at home and abroad, such as time series, linear regression analysis, support vector machine, artificial neural network model, grey system model. The scientific and reasonable settlement prediction model is not only beneficial to the safety of buildings, but also important to the decision making. [1-3]

Established by Chinese scholar professor Deng Julong in 1982, grey system theory is a method specially used to study the problem of uncertain systems in which some information is known and some information is unknown. 4 The grey prediction model can be divided into univariate grey prediction model and multivariate grey prediction model according to the number of modeling variables. The univariate grey prediction model is represented by $\mathrm{GM}(1,1)$, whose modeling object is only one time series data. It mainly mines the system operation law contained in the time series data through the grey generation method, and then realizes the prediction of the system development trend. The multivariable grey prediction model is represented by $\operatorname{GM}(1, N)$. The modeling object of this model is composed of a system feature sequence and $\mathrm{n}-1$ correlation factor sequence. The modeling process fully considers the influence of correlation factors on the change trend of the system. However, the model has many shortcomings in modeling mechanism and structure. So many scholars have improved $\operatorname{GM}(1,1)$, such as Railway passenger volume prediction based on GA-GM $(1, \mathrm{~N}, \alpha)$ power model by $\mathrm{Xu}$ Kun[8], Prediction of corrosion rate of carbon steel based on $\mathrm{GM}(1, \mathrm{~N})$ model by Zheng Ruyan[9], Real estate price forecast of Zhengzhou based on GM $(1, N)$ model by Zhang Rongyan[10], Study on groundwater salinity in Linzhang county based on GM (1, N) model by Zhang Ziyue[11], Research on the accuracy of optimized grey $\mathrm{GM}(1, \mathrm{~N})$-weighted Markov model in road traffic noise prediction by Huang Chaoqiang[12]. At present, grey prediction model has been widely used in fields such as urban environment, traffic management, energy analysis.[5-7]

It can be seen from the above literatures that there are still defects in multivariate gray prediction. Therefore, this paper combines the traditional multivariate gray prediction with the new information priority in the axiom of gray system, defines the accumulation generation with parameter form, and establishes a multivariate gray prediction model with new information priority accumulation.

\footnotetext{
*Corresponding author: zhanglanxi1203@163.com
} 


\section{Traditional multivariate grey prediction model}

Definition 1. Set $X_{1}^{(0)}$ as a sequence of dependent variables 13 :

$$
X_{1}^{(0)}=\left(X_{1}^{(0)}(1), X_{1}^{(0)}(2), \ldots, X_{1}^{(0)}(m)\right)
$$

The sequence $X_{i}^{(0)}(i=1,2, \ldots, N)$ is the sequence of independent variables with high correlation with sequence $X_{1}^{(0)}$.

$$
X_{i}^{(0)}=\left(X_{i}^{(0)}(1), X_{i}^{(0)}(2), \ldots, X_{i}^{(0)}(m)\right)
$$

$X_{i}^{(1)}$ is the first order cumulative sequence of $X_{i}^{(0)}$ $(i=1,2, \ldots, N)$.

$$
X_{i}^{(1)}=\left(X_{i}^{(1)}(1), X_{i}^{(1)}(2), \ldots, X_{i}^{(1)}(m)\right)
$$

Where

$$
\begin{aligned}
& X_{i}^{(1)}(k)=\sum_{j=1}^{k} X_{i}^{(0)}(k) \\
k=1,2, \ldots, m &
\end{aligned}
$$

$Z_{i}^{(1)}$ is the sequence generated next to the mean of ${ }^{X_{i}^{(1)}}$ :

$$
Z_{i}^{(1)}=\left(Z_{i}^{(1)}(2), Z_{i}^{(1)}(3), \ldots, Z_{i}^{(1)}(m)\right)
$$

Where

$$
\begin{aligned}
& \quad Z_{j}^{(1)}(k)=0.5 \times\left(X_{j}^{(1)}(k)+X_{j}^{(1)}(k-1)\right) \\
& k=1,2, \ldots, m
\end{aligned}
$$

So

$$
\begin{aligned}
& X_{1}^{(0)}(k)+a Z_{1}^{(1)}(k) \\
& =b_{2} X_{2}^{(1)}(k)+b_{3} X_{3}^{(1)}(k)+\ldots+b_{N} X_{N}^{(1)}(k)
\end{aligned}
$$

is called traditional multivariate gray prediction model

Theorem $1 X_{i}^{(0)}, X_{i}^{(1)}(i=1,2, \ldots, N)$ and $Z_{1}^{(1)}$ refer to definition 1 , Then, the least square estimation of the parameter $\hat{a}=\left[a, b_{2}, \ldots, b_{N}\right]^{T}$ of the traditional multivariate gray prediction model is satisfied

1) If $\mathrm{m}=\mathrm{N}+1$ and $|B| \neq 0$ then $\hat{a}=B^{-1} Y$;

2) If $\mathrm{m}>\mathrm{N}+1$ and $\left|B^{T} B\right| \neq 0$ then $\hat{a}=\left(B^{T} B\right)^{-1} B^{T} Y$;

3) If $\mathrm{m}<\mathrm{N}+1$ and $\left|B^{T} B\right| \neq 0$ then

$\hat{a}=B^{T}\left(B^{T} B\right)^{-1} Y$;

Where

$$
\begin{aligned}
& B=\left(\begin{array}{ccc}
-Z_{1}^{(1)}(2) & X_{2}^{(1)}(2) & \mathrm{L} X_{2}^{(1)}(2) \\
-Z_{1}^{(1)}(3) & X_{2}^{(1)}(3) & \mathrm{L} X_{2}^{(1)}(2) \\
\mathrm{M} & \mathrm{M} & \mathrm{M} \\
-Z_{1}^{(1)}(\mathrm{m}) & X_{2}^{(1)}(2) & \mathrm{K} X_{2}^{(1)}(2)
\end{array}\right) \\
& \mathrm{Y}=\left(\begin{array}{c}
X_{1}^{(0)}(2) \\
X_{1}^{(0)}(3) \\
\mathrm{M} \\
X_{1}^{(0)}(m)
\end{array}\right)
\end{aligned}
$$

Proof 1 When $\mathrm{k}=2,3, \ldots, \mathrm{m}$, from Eq. (7), we have

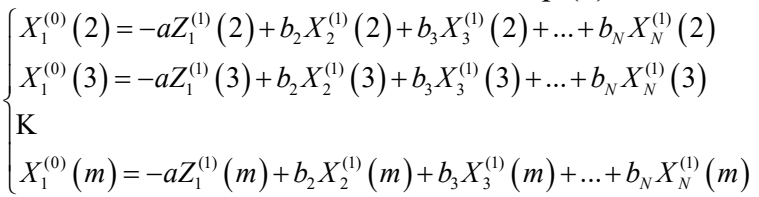

In matrix form:

$$
Y=\mathrm{B} \hat{a}
$$

If $\mathrm{m}=\mathrm{N}+1$ and $|B| \neq 0$ then $\hat{a}=B^{-1} Y$;

If $\mathrm{m}>\mathrm{N}+1$ and $\left|B^{T} B\right| \neq 0$ then $\hat{a}=\left(B^{T} B\right)^{-1} B^{T} Y$;

When $\mathrm{m}<\mathrm{N}+1$, B is a column full rank matrix, and $\left|B^{T} B\right| \neq 0$, the column full rank decomposition of $\mathrm{B}$ is:

$$
\mathrm{B}=\mathrm{DC}
$$

Therefore, the generalized inverse matrix $B^{+}$of $\mathrm{B}$ is as follows:

$$
B^{+}=C^{T}\left(C C^{T}\right)^{-1}\left(D^{T} D\right)^{-1} D^{T}
$$

And we have

$$
\hat{a}=C^{T}\left(C C^{T}\right)^{-1}\left(D^{T} D\right)^{-1} D^{T} Y
$$

Let's take D as the identity matrix $I_{n-1}$ and we have

$$
\hat{a}=B^{T}\left(B^{T} B\right)^{-1} Y
$$

End of proof. 16

Definition 2 Linear differential equation

$$
\begin{aligned}
& \frac{d X_{1}^{(1)}}{d t}+a X_{1}^{(1)}(t) \\
& =b_{2} X_{2}^{(1)}(t)+b_{3} X_{3}^{(1)}(t)+\ldots+b_{N} X_{N}^{(1)}(t)
\end{aligned}
$$

is called the whitening equation of the traditional multivariate gray prediction model.

Theorem 2 When the change range of $X_{j}^{(1)}(j=2,3, \ldots, N)$ is small, $\sum_{j=2}^{N} b_{j} X_{j}^{(1)}(t)$ can be regarded as the grey constant, and the time response equation 14 of the traditional multivariate grey prediction model is:

$$
\hat{X}_{1}^{(1)}(k)=\left[X_{1}^{(0)}(1)-\frac{1}{a} \sum_{j=2}^{N} b_{j} X_{j}^{(1)}(1)\right] e^{-a(k-1)}+\frac{1}{a} \sum_{j=2}^{N} b_{j} X_{j}^{(1)}(k)
$$

Reduction type:

$$
\begin{gathered}
\hat{X}_{1}^{(0)}(1)=X_{1}^{(1)}(1) \\
\hat{X}_{1}^{(0)}(k)=\hat{X}_{1}^{(1)}(k)-\hat{X}_{1}^{(1)}(k-1) \\
k=1,2, \ldots, m
\end{gathered}
$$

Proof 2 The solution of equation (10) is:

$$
X_{1}^{(1)}(t)=X_{1}^{(1)}(1) e^{-a(t-1)}+\int_{1}^{t} e^{-a(t-\tau)} \sum_{j=2}^{N} b_{j} X_{j}^{(1)}(\tau) d \tau
$$

When the change range of $X_{j}^{(1)}(j=2,3, \ldots, N)$ is small, $\sum_{j=2}^{N} b_{j} X_{j}^{(1)}(t)$ convolution in equation (13) can be written as

$$
\int_{1}^{t} e^{-a(t-\tau)} \sum_{j=2}^{N} b_{j} X_{j}^{(1)}(\tau) d \tau
$$




$$
\begin{aligned}
& =\sum_{j=2}^{N} b_{j} X_{j}^{(1)}(t) \int_{1}^{t} e^{-a(t-\tau)} d \tau \\
& =\frac{1}{a}\left(1-e^{-a(t-1)}\right) \sum_{j=2}^{N} b_{j} X_{j}^{(1)}(t)
\end{aligned}
$$

Substitute (14) into (13), take $\mathrm{t}=\mathrm{k}$, then

$$
\begin{aligned}
X_{1}^{(1)}(k) & =X_{1}^{(1)}(1) e^{-a(k-1)}+\frac{1}{a}\left(1-e^{-a(k-1)}\right) \sum_{j=2}^{N} b_{j} X_{j}^{(1)}(k) \\
& =\left[X_{1}^{(0)}(1)-\frac{1}{a} \sum_{j=2}^{N} b_{j} X_{j}^{(1)}(1)\right] e^{-a(k-1)}+\frac{1}{a} \sum_{j=2}^{N} b_{j} X_{j}^{(1)}(k)
\end{aligned}
$$

End of proof.

\section{Traditional multivariate gray prediction model based on new interest priority}

In the grey system principle, it can be known from the principle of new information priority that the role of new information cognition is greater than the role of old information, which directly affects the future trend of the system and plays a major role in the future development of realistic information. Therefore, this paper defines cumulative generation with parameter form 15 .

Definition 2 Set $X_{1}^{(0)}$ as a sequence of dependent variables:

$$
X_{1}^{(0)}=\left(X_{1}^{(0)}(1), X_{1}^{(0)}(2), \ldots, X_{1}^{(0)}(m)\right)
$$

The sequence $X_{i}^{(0)}(i=1,2, \ldots, N)$ is the sequence of independent variables with high correlation with sequence:

$$
X_{i}^{(0)}=\left(X_{i}^{(0)}(1), X_{i}^{(0)}(2), \ldots, X_{i}^{(0)}(m)\right)
$$

$X_{i}^{(1)}$ is the first order cumulative sequence of $X_{i}^{(0)}$ $(i=1,2, \ldots, N)$.

$$
X_{i}^{(1)}=\left(X_{i}^{(1)}(1), X_{i}^{(1)}(2) \ldots, X_{i}^{(1)}(m)\right)
$$

where $^{\lambda \in(0,1)}$, so

$$
\begin{gathered}
X_{i}^{(1)}(k)=\sum_{j=1}^{k} \lambda^{m-j} X_{i}^{(0)}(k) \\
k=1,2, \ldots, m
\end{gathered}
$$

$Z_{i}^{(1)}$ is the sequence generated next to the mean of $X_{i}^{(1)}$.

$$
Z_{i}^{(1)}=\left(Z_{i}^{(1)}(2), Z_{i}^{(1)}(3), \ldots, Z_{i}^{(1)}(m)\right)
$$

where

\begin{tabular}{|c|c|c|c|c|c|c|c|}
\hline \multicolumn{8}{|c|}{ Cumulative settlement $/ \mathrm{mm}$} \\
\hline cycle & $\begin{array}{l}\text { The total number of } \\
\text { days }\end{array}$ & load & A410 & A403 & A405 & A410 & $\begin{array}{l}\text { Overall trend } \\
\text { settlement }\end{array}$ \\
\hline 1 & 0 & 3 & 0.67 & 0.82 & 0.71 & 1.03 & 0.76 \\
\hline 2 & 17 & 6 & 1.48 & 1.57 & 1.35 & 1.9 & 1.5 \\
\hline 3 & 36 & 9 & 2.22 & 2.23 & 1.96 & 2.72 & 2.2 \\
\hline 4 & 54 & 12 & 2.9 & 2.8 & 2.46 & 3.5 & 2.83 \\
\hline 5 & 70 & 15 & 3.49 & 3.56 & 2.85 & 4.31 & 3.47 \\
\hline 6 & 91 & 18 & 4.12 & 4.15 & 3.13 & 5.25 & 4.14 \\
\hline 7 & 108 & 21 & 4.9 & 4.81 & 3.36 & 6.04 & 4.74 \\
\hline 8 & 127 & 24 & 5.42 & 5.52 & 3.54 & 6.67 & 5.27 \\
\hline 9 & 143 & 24 & 5.73 & 5.96 & 3.79 & 7.27 & 5.66 \\
\hline 10 & 162 & 24 & 6.01 & 6.25 & 3.96 & 7.69 & 5.93 \\
\hline 11 & 182 & 24 & 6.23 & 6.42 & 4.09 & 8.01 & 6.11 \\
\hline
\end{tabular}

$$
\begin{gathered}
Z_{j}^{(1)}(k)=0.5\left(X_{j}^{(1)}(k)+X_{j}^{(1)}(k-1)\right) \\
k=1,2, \ldots, m
\end{gathered}
$$

so

$X_{1}^{(0)}(k)+a Z_{1}^{(1)}(k)=b_{2} X_{2}^{(1)}(k)+b_{3} X_{3}^{(1)}(k)+\ldots+b_{N} X_{N}^{(1)}(k)$

is the traditional multivariate gray prediction model based on new information priority, $\operatorname{NIPGM}(1, N)$ model for short.

Table 1 Original settlement observation data

Table 2 Model data accuracy comparison (unit: $\mathrm{mm}$ )

\begin{tabular}{cccccccc}
\hline & & \multicolumn{2}{c}{ NIPGM $(1, \mathrm{~N})$ model } & \multicolumn{2}{c}{ GM(1,1) model } & \multicolumn{2}{c}{ DGM(1,1) model } \\
\cline { 3 - 7 } cycle & observations & $\begin{array}{c}\text { Predictive } \\
\text { value }\end{array}$ & $\begin{array}{c}\text { Relative } \\
\text { error }\end{array}$ & $\begin{array}{c}\text { Predictive } \\
\text { value }\end{array}$ & $\begin{array}{c}\text { Relative } \\
\text { error }\end{array}$ & $\begin{array}{c}\text { Predictive } \\
\text { value }\end{array}$ & $\begin{array}{c}\text { Relative } \\
\text { error }\end{array}$ \\
\hline 1 & 0.76 & 0.7600 & 0 & 0.7600 & 0 & 0.7600 & 0 \\
2 & 1.50 & 1.2093 & 0.2907 & 2.3697 & 0.8697 & 2.3850 & 0.885 \\
3 & 2.20 & 2.2624 & 0.0624 & 2.6666 & 0.4666 & 2.6822 & 0.4822 \\
4 & 2.83 & 2.8355 & 0.0055 & 3.0008 & 0.1708 & 3.0164 & 0.1864
\end{tabular}




\begin{tabular}{cccccccc}
5 & 3.47 & 3.4093 & 0.0607 & 3.3768 & 0.0932 & 3.3923 & 0.0777 \\
6 & 4.14 & 4.0199 & 0.1201 & 3.8000 & 0.34 & 3.8150 & 0.325 \\
7 & 4.74 & 4.7802 & 0.0402 & 4.2762 & 0.4638 & 4.2904 & 0.4496 \\
8 & 5.27 & 5.2874 & 0.0174 & 4.8121 & 0.4579 & 4.8251 & 0.4449 \\
9 & 5.66 & 5.5898 & 0.0702 & 5.4151 & 0.2449 & 5.4263 & 0.2337 \\
10 & 5.93 & 5.8629 & 0.0671 & 6.0937 & 0.1637 & 6.1025 & 0.1725 \\
11 & 6.11 & 6.0775 & 0.0325 & 6.8573 & 0.7473 & 6.8629 & 0.7529 \\
\multicolumn{2}{r}{} & MAPE & $2.8959 \%$ & $12.1739 \%$ & $12.2622 \%$ \\
\hline
\end{tabular}

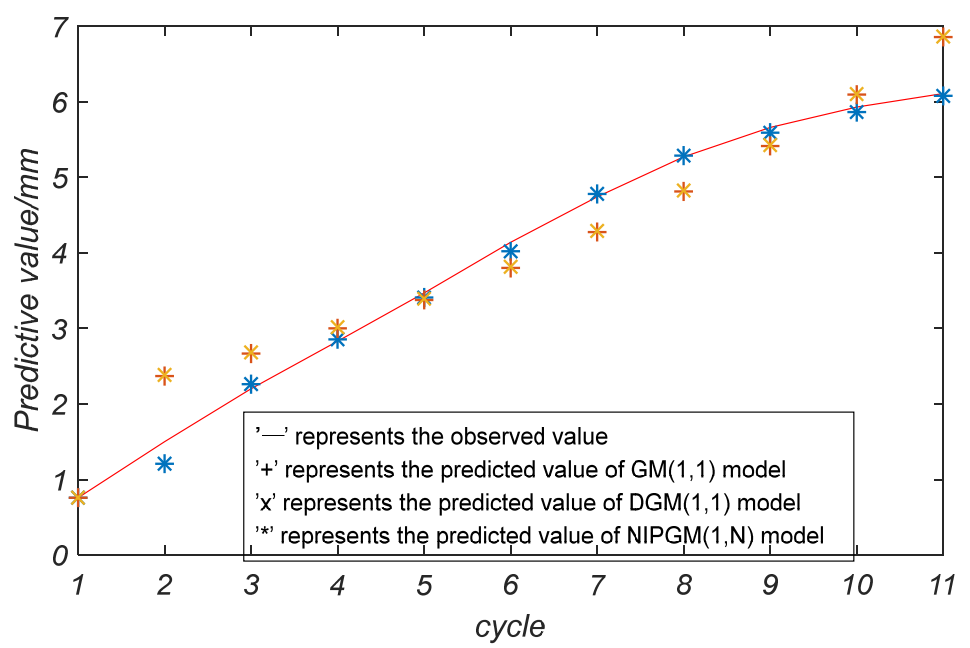

Fig. 1. Model data comparison
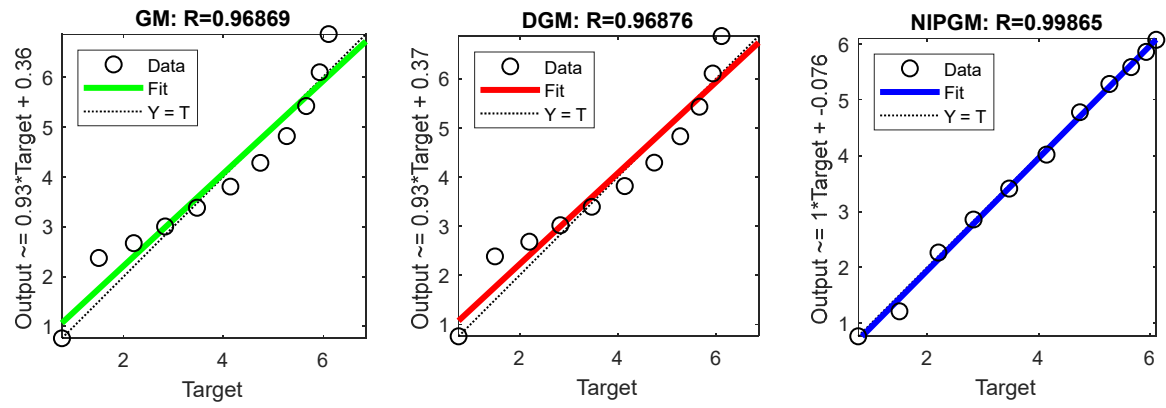

Fig. 2. Return to figure

\section{The example analysis}

This paper, taking a A4 building project in Anhui province as an example[16], sedimentation analysis application $\operatorname{NIPGM}(1, \mathrm{~N})$ model, the dependent variable of the trend of settlement as a whole, before 4 issue of the settlement observation data as the known data, on the basis of settlement observation data of 5 to 7 as a search for the parameters of the accumulation generation sequence, and thereby to 8 and the basis of settlement observation data to predict.

\subsection{The observed data}

A total of 10 observation points are set up in building A4, from which observation points were randomly selected for data analysis.

\subsection{Settlement analysis bases on the traditional multivariable grey prediction model of new interest priority}

The observation point A401 is taken as the sequence of independent variables, and the overall trend settlement is the sequence of dependent variables. $\operatorname{NIPGM}(1, \mathrm{~N})$ model is used to predict the settlement. For the overall trend settlement, the predicted value of the three models and the relative error comparison between the predicted value and the observed value are shown in table 2 . The data of the three models and the observed value are shown in figure 1. The regression diagram of the three models is shown in figure 2. 
As can be seen from figure 1, the predicted value obtained by the $\operatorname{NIPGM}(1, N)$ model is closer to the observed value curve with a small error. However, the predicted values of $\operatorname{GM}(1,1)$ model and $\operatorname{DGM}(1,1)$ model are far from the observed values, and the errors are large.

From figure 2, we can also see that the $\operatorname{NIPGM}(1, N)$ model can be better fitted by the regression equation. The correlation coefficient of $\operatorname{NIPGM}(1, \mathrm{~N})$ model regression graph $\mathrm{R}=0.99865$, the correlation coefficient of $\mathrm{GM}(1, \mathrm{~N})$ model regression graph $\mathrm{R}=0.96869$, the correlation coefficient of $\operatorname{DGM}(1, \mathrm{~N})$ model regression graph $\mathrm{R}=0.96876$. The correlation coefficient of $\operatorname{NIPGM}(1, \mathrm{~N})$ model is closer to 1 than that of $\operatorname{GM}(1,1)$ model and $\operatorname{DGM}(1,1)$ model. In summary, the predicted value of $\operatorname{NIPGM}(1, N)$ model is consistent with the observed value, and the relative error is small. The prediction effect is better than that of $\operatorname{GM}(1,1)$ model and $\operatorname{DGM}(1,1)$ model.

\section{Conclusion}

The observation of building settlement is affected by many factors, and each monitoring station also affects and restricts each other. If only the influence of individual factors is considered, there may be a large error. Therefore, this paper considers the multivariate grey prediction model, and uses the new information first principle to improve the background value of the traditional multivariate grey model. Therefore, $\operatorname{NIPGM}(1, \mathrm{~N})$ model was proposed to reduce the error and obtain more accurate results. Taking A4 floor of an engineering project in Anhui Province as an example, the settlement analysis is carried out, and compared with GM $(1,1)$ model and DGM $(1,1)$ model, it can be seen that the established model has a better effect. The prediction effect and higher reliability provide an effective method for future prediction analysis.

\section{References}

1. C.Shu, Z.Longfei, G.Xianglin. GIS. Application of grey correlation $\mathrm{GM}(1, \mathrm{~N})$ model in settlement analysis of buildings [J]. 42(05):10-13.2019

2. Y.Shian. ECIT. Application of optimized grey markov model in prediction of building subsidence [D]. 2014.

3. L.Zhiwei, 1.Kezhao, Z.Leijie, W.Yunkai. GIS Application of multivariable grey markov model in prediction of building subsidence [J]. 43 (03) : 3640.2008

4. Z.Bo, Y.Xiaoyong, M.Wei. Science. Realization of grey prediction modeling method and its MATLAB program.

5. Lian R J. MedSci. Enhanced adaptive grey-prediction self-organizing fuzzy sliding-mode controller for robotic systems[J]. 236(1): 186-204.2012

6. Chang $\mathrm{T} \mathrm{S}, \mathrm{Ku} \mathrm{C} \mathrm{Y}, \mathrm{Fu} \mathrm{H}$ P. Technological Forecasting \& Social Change Grey theory analysis of online population and online game industry revenue in Taiwan[J]. 80(1): 175-185.2013

7. Xia.M, Wong.W.K. Knowledge-Based Systems. A seasonal discrete grey forecasting model for fashion
retailing[J]. 57(2): 119-126.2014

8. X.Kun, B.Xuying ,W.Qicai. Railway standard design .Based on GA - GM (1, N, alpha) power model of railway passenger traffic prediction [J]. (01)6-10. 2018

9. Z.Ruyan,P.Fei, M.Jinlei. China ship. Prediction of corrosion rate of carbon steel based on $\operatorname{GM}(1, \mathrm{~N})$ model [J]. 13 (01) : 60-64 + 113.2008

10. Z.RongYan. Mathematical practice and understanding. Real estate price forecast in zhengzhou based on GM $(1, N)$ model [J]. 48 (05) : 82-88.2008

11. Z.Ziyue, D.Fuhui, L. Mingran, L.Xinde, W.Yuan. China rural water conservancy and hydropower.Study on groundwater salinity in Linzhang county based on GM $(1, \mathrm{~N})$ model [J]. (07) : 74-77.2018

12. H.Zhaoqiang, L.Jiding, Y.Banghua. Journal of nanhua university (natural science edition). research on the accuracy of optimized grey GM $(1, N)$-weighted Markov model in road traffic noise prediction [J]. 203,33 (01) : 35-43. (in Chinese)

13. Z.Liang. Journal of southwest university (natural science edition) Modified grey multivariate $\mathrm{GM}(1, \mathrm{~N})$ model and its application [J]. 41(09):68-76.2019

14. M.Xin. Southwest petroleum university. Study on reservoir performance prediction based on grey system and nuclear method [D]. 2016.

15. Z.Weijie,Z.Hongju,D.Yao-guo,Z.Xin. China science of management. Construction and application of grey discrete model of new information first accumulation [J]. 25(08):140-148.2017

16. W.Zhengxin. Systems engineering theory and practice. Grey multivariable GM $(1, \mathrm{~N})$ power model and its application [J]. 34 (09) : 2357-2363.2014 